\title{
Opéra des émeutes: les musiques jeunes, de la rue à la reconnaissance
}

Pierre Raboud

\section{(2) OpenEdition \\ 1 Journals}

Édition électronique

URL : http://journals.openedition.org/edl/2446

DOI : $10.4000 /$ edl.2446

ISSN : 2296-5084

Éditeur

Université de Lausanne

\section{Édition imprimée}

Date de publication : 15 mars 2020

Pagination : 205-208

ISBN : 978-2-940331-73-4

ISSN : 0014-2026

\section{Référence électronique}

Pierre Raboud, "Opéra des émeutes: les musiques jeunes, de la rue à la reconnaissance », Études de lettres [En ligne], 312 | 2020, mis en ligne le 24 mars 2020, consulté le 10 décembre 2020. URL : http:// journals.openedition.org/edl/2446 ; DOI : https://doi.org/10.4000/edl.2446 


\section{OPÉRA DES ÉMEUTES: LES MUSIQUES JEUNES, DE LA RUE À LA RECONNAISSANCE}

Mai 1980: deux événements, sans lien apparent, adviennent quasiment en même temps. Un concert du chanteur reggae jamaïquain Bob Marley a lieu à la salle du Volkhaus le 30. Ce même mois, la municipalité de Zurich vient d'accorder un nouveau crédit de soixante millions à l'Opéra de la ville. C'est peut-être dans la rencontre fortuite de ces deux événements que se joue une période de mobilisation en Suisse et, dans son sillon, un tournant pour la culture suisse. D'un côté, on retrouve dans le paysage culturel helvétique une politique culturelle centrée sur les pratiques bourgeoises et prestigieuses. De l'autre, une culture jeune volontiers subversive existe bien, mais reste cantonnée aux grandes salles réservées quasiment exclusivement aux stars connues à l'international.

En effet, en 1980, il n'existe que très peu de lieux pour pratiquer ou écouter des musiques jeunes ou alternatives. Sans mettre en place des pratiques répressives, les gouvernements suisses (tant locaux que fédéraux) ne développent pas de promotion de ce type de pratiques. Le besoin de lieu va se traduire en mélodies et en actes. Sur le plan musical émergent des nouveaux genres ayant en commun un dédain pour les musiques commerciales et le rock mainstream, queue de comète des contre-cultures des années 1960 et 1970, avec leurs mégagroupes et leur fétichisation de la virtuosité musicale. Reggae, punk et autres entendent réinsuffler de la colère dans la musique en jouant sans maitrise et en chantant fort le rejet de la société suisse. "Zurich brûle. La ville des vieux cons» entonnent les Zurichois de TNT.

En actes, tout commence avec les «émeutes de l'Opéra de Zurich». Ces dernières font événement au point d'être rapidement désignées par une 
expression consacrée (Opernhaus Krawalle). Cette mobilisation rassemble plusieurs centaines de jeunes, dont certains viennent directement du concert de Bob Marley, pour dénoncer le budget dévoué à ce lieu et l'absence de soutien aux cultures jeunes. Elle débouche sur des affrontements avec la police et aura de nombreuses suites. À Zurich, mais aussi dans la plupart des grandes villes du pays (Lausanne, Berne, Bâle, Lucerne, etc.), 1980 sera une année rythmée par les manifestations rassemblant jusqu’à plusieurs milliers de jeunes. Dans cette révolte, différentes revendications s'entrecroisent: la demande de lieu de concert, mais aussi une remise en cause de l'espace urbain, de l'économie du logement ou encore la revendication de la légalisation des drogues. Le répertoire d'action ne s'arrête pas aux manifestations. Dans chaque ville, des groupes de musique se forment; des collectifs éditent des publications politiques en reprenant le modèle des fanzines punks; des maisons, des friches sont occupées avec un mot d'ordre promis à faire florès: l'autonomie.

Si ces années de mobilisation interpellent, c'est parce qu'elles vont marquer un tournant. De l'absence de lieux, les villes de Suisse vont se transformer pour ensuite accueillir de nombreuses salles destinées aux musiques jeunes où peuvent se produire des formations locales. La Rote Fabrik (Zurich) et la Kaserne (Bâle) ouvrent en 1980, la Reitschule (Berne) en 1981, Fri-Son en 1983, et enfin la Dolce Vita en 1984. À l'exception du dernier cas, ces lieux constituent toujours aujourd'hui des centres névralgiques de la culture alternative et jeune en Suisse. De la rue à la reconnaissance, le chemin est passé évidemment par des processus d'institutionnalisation. Après avoir répondu par la répression, la ville de Zurich définit une stratégie modèle appelée à être reproduite ailleurs: refuser à ces mobilisations toute légitimité politique pour les réduire à des demandes strictement culturelles. La recommandation est alors de soutenir ces dernières pour scinder le mouvement et normaliser la situation. Cette politique sera couronnée de succès. Elle débouche sur l'instigation d'un Pop Kredit en 1984, la répression cédant la place à la subvention.

Les émeutes de l'Opéra ont ainsi participé au changement du visage de la Suisse, en forçant son ouverture à d'autres formes de pratiques culturelles. Mais cette dynamique se fait sous l'auspice de la récupération, vidant la sève revendicative de l'autonomie.

Pierre Raboud

Section d'histoire, Faculté des lettres, Université de Lausanne 


\section{BIBLIOGRAPHIE}

Braendle, Christoph, Zürich brennt, Zürich, Europa Verlag, 2010.

Buchs, Valérie, Bonnet, Nelly, Lagier, Diane, Cultures en urgence. Mouvements contre-culturels: de l'alternance à l'intégration, Genève, I.E.S., 1988.

Grand, Lurker, Tschan, André P. (eds), Hot Love, Swiss Punk\&Wave. 1976-1980, Zürich, Édition Patrick Frey, 2006.

- (Hrsg.), Heute und Danach. The Swiss Underground Scene's of the 80s, Zürich, Patrick Frey, 2011.

KöNIg, Mario et al. (Hrsg.), Dynamisierung und Umbau: die Schweiz in den 60er und 70er Jahren, Zürich, Chronos, 1998.

Kriesi, Hanspeter, Die Zürcher Bewegung, Frankfurt, Campus Verlag, 1984.

Kriesi, Hanspeter, Levy, René, Ganguillet, Gilbert, Zwicky, Heinz (Hrsg.), Politische Aktivierung in der Schweiz, Diessenhofen, Verlag Ruegger, 1981.

Kriesi, Hanspeter et al., New Social Movements in Western Europe. A Comparative Analysis, Minneapolis, University of Minnesota Press, 1995.

Kriesi, Hanspeter, Trechse, Alexander H., The Politics of Switzerland: Continuity and Change in a Consensus Democracy, Cambridge, Cambridge University Press, 2008.

Marguerat, Dimitri, Lozane bouge "Un vieux rêve... un centre autonome»: un mouvement atypique dans la culture politique vaudoise, Mémoire de maîtrise universitaire, Université de Lausanne, 2011.

Nigg, Heinz (Hrsg.), Wir wollen alles, und zwar subito!, Die Achtiger Jugendunruhen in der Schweiz und ihre Folgen, Zürich, Limmat Verlag, 2001. 
